\title{
Growing season precipitation in Finland under recent and projected climate
}

\author{
J. S. Ylhäisi ${ }^{1}$, H. Tietäväinen, ${ }^{2}$, P. Peltonen-Sainio ${ }^{3}$, A. Venäläinen ${ }^{2}$, J. Eklund ${ }^{1}$, J. Räisänen ${ }^{1}$, and K. Jylhä ${ }^{2}$ \\ ${ }^{1}$ Department of Physics, University of Helsinki, P.O. Box 48, 00014 University of Helsinki, Finland \\ ${ }^{2}$ Finnish Meteorological Institute, P.O. Box 503, 00101 Helsinki, Finland \\ ${ }^{3}$ MTT Agrifood Research Finland, 31600 Jokioinen, Finland
}

Received: 18 December 2009 - Revised: 15 June 2010 - Accepted: 5 July 2010 - Published: 16 July 2010

\begin{abstract}
The past and projected future precipitation sum in May-September for two areas in Finland, one located in the south-west (SW) and the other in the north-east (NE), is studied using 13 regional climate simulations and three observational datasets. The conditions in the present-day climate for agricultural crop production are far more favourable in the south-western part of the country than the more continental north-eastern Finland. Based on a new high-resolution observational precipitation dataset for Finland (FMI_grid), with a resolution of $10 \times 10 \mathrm{~km}$, the only statistically significant past long-term (1908-2008) precipitation tendencies in the two study regions are positive. Differences between FMI_grid and two other observational datasets during 1961-2000 are rather large in the $\mathrm{NE}$, whereas in the SW the datasets agree better. Observational uncertainties stem from the interpolation and sampling errors. The projected increases in precipitation in the early stage of the growing season would be most favourable for agricultural productivity, but the projected increases in August and September might be harmful. Model projections for the future indicate a statistically significant increase in precipitation for most of the growing season by 2100 , but the distribution of precipitation within the growing season is not necessarily the most optimal.
\end{abstract}

\section{Introduction}

Northern Europe lies within the temperate or boreal climate zones, where the precipitation is, on average, moderate in all seasons. With temperature increasing in the projected future climate, the moisture holding capacity of the atmosphere will

Correspondence to: J. S. Ylhäisi

(jussi.s.ylhaisi@helsinki.fi) also increase (Lenderink and Van Meijgaard, 2008). This is also reflected in the average precipitation amounts, which are expected to increase over Northern Europe (e.g. Kendon et al., 2009). The largest fractional increase in precipitation is expected to take place in winter, whereas the increase is more modest for the growing season (Christensen and Christensen, 2007). Projections of simulated precipitation provide important information for many parts of society, such as agriculture, when concerning adaption to climate change in the 21 st century.

Field crop production is rainfed in Finland. From an agronomic perspective, precipitation generally falls unevenly in time and opposite to the requirements of major, spring sown field crops. Early summer drought often interferes with the plant stand establishment of field crops that are typically sown in May. It also interferes with crop development and growth at the most critical phases of yield determination, thereby causing frequent yield losses (Peltonen-Sainio et al., 2009a). As an example, for spring barley (Hordeum vulgare L.) only about $30-60 \%$ of the precipitation needed for undisturbed yield formation fell on average over three decades, depending on the region (Peltonen-Sainio et al., 2010). Such a water deficit at the early growth stages resulted in yield losses averaging $7-17 \%$ over a 30 -year period, again depending on the region. Yield reduction was highest in the coastal regions of south-western Finland and lowest in northeastern Finland. Due to the longer growing season and higher cumulated degree days, south-western Finland has higher yield potentials and field crop production intensity relative to the marginal north-eastern parts of the country. On the other hand, precipitation typically becomes more frequent and abundant for both areas as the growing season proceeds. In late July, August and September, precipitation no longer promotes growth or compensates for yield losses caused by

Published by Copernicus Publications on behalf of the European Geosciences Union. 
insufficient water during the early growth stages in May and June. Abundant late summer rain may even be damaging for the harvest and cause additional energy costs due to the higher demand for seed drying. Abundant rain also causes lodging and a humid microclimate for the plant stands, which results in quality losses and e.g. Fusarium spp. invasions. Furthermore, waterlogged soils do not bear harvesting machinery, which again causes a high risk for soil compaction (Peltonen-Sainio et al., 2009a).

In the future, yield potentials of current major field crops are estimated to be markedly higher than today and novel or presently marginal field crops are likely to be introduced to Finnish cultivation as a consequence of elevated temperatures and a prolonging of the growing season (PeltonenSainio et al., 2009b). However, higher yields and biomasses will require more water than at present and pressure for evapotranspiration will also increase at elevated temperatures. Furthermore, precipitation distributed evenly in time is far more favourable for crop growth than less frequent, heavy showers. Hence, water availability, even in the case of no changes in the total monthly precipitation, may cause additional challenges for the future crop production. Precipitation is a key attribute for yield formation, variability and general production uncertainty of major field crops grown in Finland.

Areal estimates of observed or simulated precipitation are normally obtained from gridded datasets, which contain numerous sources of uncertainty. Firstly, the accuracy of the interpolation procedure depends on the number of observations available, and, typically, the observation network coverage gets poorer when going back in time. Secondly, the precipitation value, usually taken to represent the mean value within a grid-box, depends on the grid-box size and the more heterogeneous the precipitation distribution within a grid-box is, the larger the uncertainty in the mean value. Thirdly, the uncertainty in the precipitation observations is larger than e.g. for temperature, because of larger measurement errors (Solantie and Junila, 1995).

This paper deals with the observed past and projected future precipitation in the growing season in Finland based on 13 regional climate simulations and three different observational datasets. The simulations and one observational dataset are provided by the ENSEMBLES climate change project (Carter et al., 2010). We also introduce a new highresolution $10 \times 10 \mathrm{~km}$ precipitation dataset for Finland, and use it to examine long-term (1908-2008) trends in monthly precipitation totals for two study areas. The performance of the regional climate simulations in representing the observed 40-year means (1961-2000) is then considered, as well as the differences between the trends in this time period in the three observational datasets. In order to construct projections for the future, a scaling method for removing biases is utilized. The likely contribution of both observed past and simulated future changes in monthly precipitation to yields will be finally discussed.

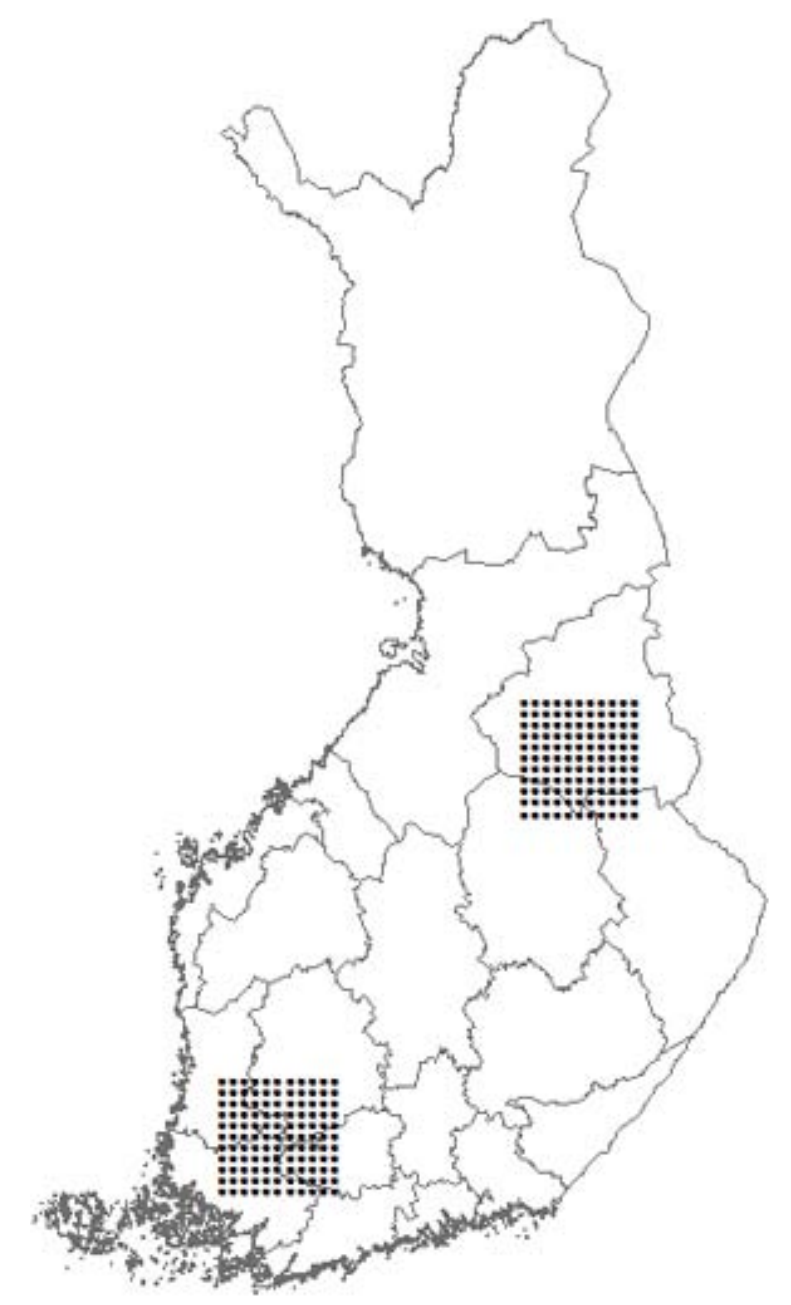

Fig. 1. Map of Finland with the study areas marked with black dots.

\section{Data and methods}

\subsection{Study areas}

We consider here the domain-averaged precipitation for two areas, both $100 \times 100 \mathrm{~km}$, one located in south-western Finland (denoted hereafter as SW), and one in north-eastern Finland (NE). These areas, shown in Fig. 1, represent different climatological subzones within the boreal main category; SW lies in the transition zone between the hemi- and south-boreal zones, and NE in the transition zone between the middle- and north-boreal zones (Solantie, 1990). In Finland, conditions for crop production are most favourable for $\mathrm{SW}$, where the thermal growing season (no snow cover, average daily temperature permanently over $+5^{\circ} \mathrm{C}$ ) lasts approximately from the beginning of May until the end of October. In $\mathrm{NE}$, the growing season is shorter, from mid-May to the end of September. In this study, the growing season period was defined as from May to September (MJJAS). 


\subsection{Observed precipitation}

Three gridded datasets of observed precipitation have been used in this study. The longest and highest-resolution dataset was developed at the Finnish Meteorological Institute (FMI), based on observed monthly precipitation sums during 19082008. The number of stations available ranged from less than 100 , at the beginning of the period, to a maximum of about 600 (Fig. 2). The spatial resolution of this gridded dataset, referred to as FMI_grid, is $10 \times 10 \mathrm{~km}$. A more detailed description of the dataset is given in Appendix A. The second dataset used was $E-O B S$ version 2.0 (Haylock et al., 2008). The E-OBS data has a 0.25 degree regular grid, which corresponds to about $25 \times 25 \mathrm{~km}$ for the study area. Monthly precipitation sums were calculated from the daily values. The third dataset was the global monthly-resolution gridded dataset CRU TS2.1 (Mitchell et al., 2005), which has a spatial resolution of $0.5 \times 0.5$ degrees. It has the coarsest resolution of the datasets used, and was interpolated bilinearly (e.g. Accadia et al., 2003) to the same grid as E-OBS.

In addition to individual monthly precipitation sums from May to September, the total seasonal sum for the five-month period from May to September was studied. The baseline period for the observed precipitation was selected to be 19612000. Also, a longer time period from 1908 to 2008 was studied from the FMI_grid dataset, to examine long-term trends in the observed precipitation.

\subsection{Simulated precipitation}

In this study, we used 13 regional climate simulations (Table 1), provided by the EU FP6 ENSEMBLES project (Carter et al., 2010). Except for ETHZ-HCO, the simulated data were readily available interpolated onto the same 0.25 degree latitude-longitude grid as used by the observational $E$-OBS dataset and included all of the climate simulations available through the ENSEMBLES distribution portal in September 2009. The simulations have been shown to contain uniform data until 2099 (Goodess et al., 2010) and all use the SRES emissions scenario A1B (Nakićenović et al., 2000).

The simulations are not independent from each other as many of them use the same driving global climate model (GCM) or regional climate model (RCM). As a consequence, this may cause the variability between the individual simulations to underestimate the actual variability compared over the complete GCM-RCM-matrix (Goodess et al., 2010) and a bias in the multi-model-mean (MMM) results. As a sensitivity test, we briefly studied two alternative weightings; one giving the same total weight for each global model (thus making the weight of an individual RCM simulation driven by a specific GCM inversely proportional to the number of RCMs driven by the same GCM), and one giving the same total weight for each regional model (thus decreasing the weight of individual simulations of those RCMs for which several simulations were available). The effects on
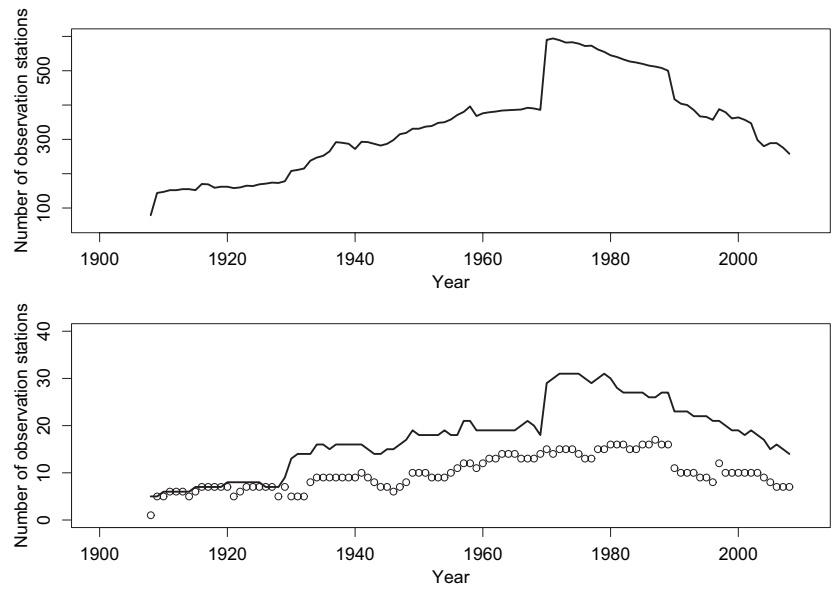

Fig. 2. Yearly number of precipitation observation stations in the entire interpolation area (top), in SW (below, solid line), and in NE (below, circles).

Table 1. Simulations used in the study. References to the models are given in Goodess et al. (2010).

\begin{tabular}{lcc}
\hline Simulation & Global model & Regional model \\
\hline C4I-HC16 & HadCM3Q0 & RCA3 \\
DMI-ARPEGE & ARPEGE & HIRHAM \\
DMI-ECHAM5 & ECHAM5-r3 & DMI-HIRHAM5 \\
ETHZ-HC0 & HadCM3Q0 & CLM \\
ICTP-ECHAM5 & ECHAM5-r3 & RegCM \\
KNMI-ECHAM5 & ECHAM5-r3 & RACMO \\
METO-HC0 & HadCM3Q0 & HadRM3Q0 \\
METO-HC3 & HadCM3Q3 & HadRM3Q3 \\
METO-HC16 & HadCM3Q16 & HadRM3Q16 \\
MPI-ECHAM5 & ECHAM5-r3 & REMO \\
SMHI-BCM & BCM & RCA \\
SMHI-ECHAM5 & ECHAM5-r3 & RCA \\
SMHI-HC3 & HadCM3Q3 & RCA \\
\hline
\end{tabular}

the multi-model-means and inter-model standard deviations were found to be very small, so the decision was taken to treat the models with a uniform weighting scheme. Another issue that might call for weighting of the simulations is their performance in present-day climate; further study of that can be found in Van der Linden and Mitchell (2009) or Räisänen et al. (2010).

Model data for two 40-year periods are used in this study; 1961-2000 as the "control" period describing the presentday climate and 2061-2100 as the scenario period. The 40year period length was selected to reduce the sampling errors resulting from internal climate variability. This argument is supported by the lower signal-to-noise ratio of precipitation changes, relative to temperature changes (Ruokolainen and Räisänen, 2007), and the large inter-decadal variability of precipitation (Tuomenvirta, 2004) compared to temperature in the Finnish climate. 

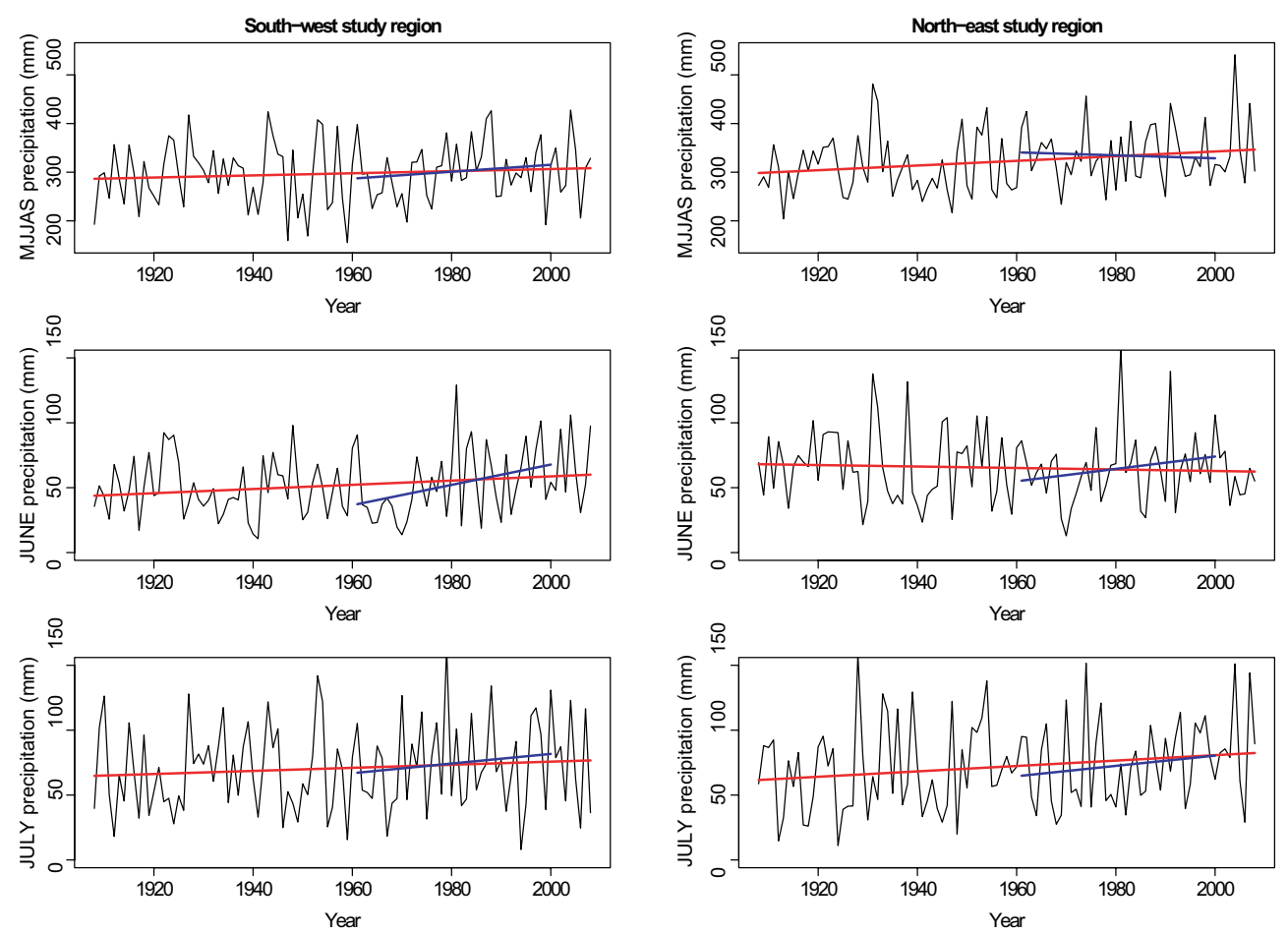

Fig. 3. Precipitation sums for 1908-2008 from May to September (top), June (middle) and July (bottom), for SW (left) and NE (right), based on FMI_grid. Trendlines for the periods 1908-2008 and 1961-2000 are shown with red and blue lines, respectively.

\subsection{Analysis methods}

Because precipitation is zero-bounded, increases in the average precipitation also imply an increase in variability, if the shape of the precipitation intensity distribution remains constant (e.g. Rowell, 2005). Nevertheless, precipitation simulations typically contain a systematic bias compared to observations that has to be removed when constructing climate scenarios. For this purpose, and for treating the variability in a consistent manner, a simple scaling method was used. For each individual simulation, all precipitation data were multiplied by a constant factor equal to the ratio between the observed precipitation sum and the simulated precipitation sum in the present-day baseline period. In this way, the mean bias was removed and the shape of the distribution was kept constant, but its width was changed proportionally to the average precipitation. This technique, where the bias of precipitation is assumed to be fractionally the same for present-day climate and future climate simulations, is widely known as the delta change method (e.g. Andersen et al., 2006). For studying the change in the mean precipitation between the two periods, a two-sided t-test was applied to the data, with a 5\% significance level (Von Storch and Zwiers, 1999). Although the monthly precipitation data are generally not normally distributed, as assumed by the $t$-test, this violation is expected to have little effect because of the relatively large sample sizes (40 vs. 40 years) used in this study (Räisänen and Joelsson,
2001). For trend analysis, the significance of the linear trends was determined by the non-parametric Kendall rank correlation coefficient, with a significance level of 5\% (Sneyers, 1990).

\section{Results}

\subsection{Mean values and trends of observed precipitation}

Time series of the monthly precipitation sum in June and July, and the cumulative sum from May to September, given in Fig. 3, reveal considerable year-to-year variations during the period 1908-2008. Linear trendlines fitted by the leastsquares method are also given in the figure for two different periods, from 1908 to 2008, and from 1961 to 2000. Statistically significant long-term tendencies were found for SW for June and for NE for May, July and MJJAS, suggesting increases in precipitation (Table 2). In many cases, however, the long-term trends were not statistically significant and varied in sign from month to month and between the two study areas.

During the baseline period 1961-2000, all three observational datasets indicated negligible changes in precipitation in May but increases in June and July (Table 2 and blue lines in Fig. 3). The only statistically significant increasing trend was found for SW in June. The trends for August and September were negative in all the datasets, but statistically 
Table 2. Trends (mm/10 years) in observed and simulated precipitation for (a) NE and (b) SW. Trends from FMI_grid are calculated from 1908-2008 and 1961-2000, trends for the period 1961-2000 are also calculated for E-OBS and CRU. The simulated trends (MMM=multimodel-mean; std =standard deviation between the models, range $=$ min and max trends between the models) are presented for the period 1961-2100. Statistically significant trends (p-value max. 0.05) are indicated with boldfacing.

\begin{tabular}{|c|c|c|c|c|c|c|c|}
\hline & \multicolumn{4}{|c|}{ Observed } & \multirow{2}{*}{\multicolumn{3}{|c|}{$\begin{array}{c}\text { Simulated } \\
1961-2100\end{array}$}} \\
\hline & \multirow{2}{*}{$\begin{array}{c}\text { 1908-2008 } \\
\text { FMI_grid }\end{array}$} & \multicolumn{3}{|c|}{ 1961-2000 } & & & \\
\hline & & FMI_grid & $E-O B S$ & $C R U$ & MMM & std & range \\
\hline \multicolumn{8}{|c|}{ (a) NE region } \\
\hline May & 2.2 & 0.6 & 0.5 & -0.1 & 1.0 & 0.6 & $0.2-\mathbf{2 . 5}$ \\
\hline Jun & -0.6 & 4.8 & 4.3 & 3.2 & 1.0 & 0.5 & $0.1-\mathbf{1 . 7}$ \\
\hline Jul & 2.1 & 4.0 & 2.8 & 2.4 & 1.0 & 0.6 & $0.1-\mathbf{2 . 1}$ \\
\hline Aug & 1.3 & -6.7 & -5.1 & -4.9 & 0.4 & 0.9 & $-1.1-2.3$ \\
\hline Sep & -0.2 & -5.7 & -6.8 & -6.8 & 0.9 & 0.7 & $-0.3-\mathbf{2 . 5}$ \\
\hline MJJAS & 4.8 & -3.1 & -4.3 & -6.2 & 4.4 & 1.9 & $0.8-\mathbf{8 . 3}$ \\
\hline
\end{tabular}

(b) SW region

\begin{tabular}{lrrrrrrr}
\hline May & -0.3 & 0.7 & 1.1 & 1.0 & $\mathbf{0 . 6}$ & 0.4 & $-0.0-\mathbf{1 . 4}$ \\
Jun & $\mathbf{1 . 6}$ & $\mathbf{7 . 8}$ & $\mathbf{9 . 4}$ & $\mathbf{4 . 7}$ & $\mathbf{0 . 5}$ & 0.6 & $-0.2-\mathbf{1 . 6}$ \\
Jul & 1.2 & 3.7 & 2.9 & 2.6 & $\mathbf{1 . 1}$ & 1.0 & $-1.1-\mathbf{2 . 3}$ \\
Aug & 0.9 & -2.0 & -3.9 & -3.4 & $\mathbf{0 . 4}$ & 1.2 & $\mathbf{- 1 . 5}-\mathbf{2 . 6}$ \\
Sep & -1.2 & -3.2 & -3.3 & -4.3 & $\mathbf{0 . 5}$ & 0.7 & $-0.8-\mathbf{1 . 5}$ \\
MJJAS & 2.2 & 7.1 & 6.2 & 0.6 & $\mathbf{3 . 2}$ & 2.8 & $-2.3-\mathbf{7 . 8}$ \\
\hline
\end{tabular}

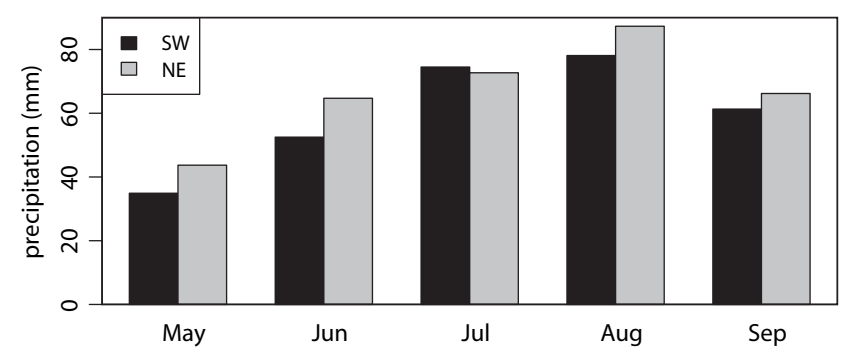

Fig. 4. Mean monthly precipitation during 1961-2000 from FMI_grid.

significant only for NE. The MJJAS trend was positive for SW and negative for NE, but neither of these was significant. Almost always, the three datasets agreed on the sign of the changes, whether these were statistically significant or not. For both areas and for nearly all studied time periods, $C R U$ has the lowest trend and FMI_grid the highest. These differences are most likely related to the different number of observation stations used in different analyses, as the error between them is mainly randomly distributed in time. For NE, MJJAS precipitation sum according to both $E-O B S$ and $C R U$ is smaller than according to $F M I_{-}$grid for every single year (not shown). For SW, and for individual months in NE, the differences between the data sets are smaller and have both positive and negative values.
Table 3. Mean values of monthly precipitation sum for 1961-2000 based on different observational datasets and precipitation simulations $(\mathrm{MMM}=$ multi-model-mean; std = standard deviation between the models) in (a) NE and (b) SW.

\begin{tabular}{|c|c|c|c|c|c|}
\hline & FMI_grid & $E-O B S$ & $C R U$ & MMM & std \\
\hline \multicolumn{6}{|c|}{ (a) NE region } \\
\hline May & 43.7 & 39.4 & 35.7 & 64.6 & 15.9 \\
\hline Jun & 64.7 & 58.7 & 56.5 & 77.3 & 16.5 \\
\hline Jul & 72.7 & 67.7 & 63.5 & 89.7 & 22.2 \\
\hline Aug & 87.3 & 79.3 & 72.6 & 94.6 & 23.2 \\
\hline Sep & 66.2 & 59.8 & 54.6 & 87.8 & 18.6 \\
\hline MJJAS & 334.5 & 304.8 & 282.8 & 414.0 & 86.0 \\
\hline \multicolumn{6}{|c|}{ (b) SW region } \\
\hline May & 34.9 & 33.3 & 33.5 & 59.8 & 11.3 \\
\hline Jun & 52.5 & 50.2 & 46.8 & 66.8 & 15.5 \\
\hline Jul & 74.5 & 74.5 & 71.4 & 74.2 & 17.6 \\
\hline Aug & 78.1 & 77.5 & 75.8 & 78.4 & 18.7 \\
\hline Sep & 61.3 & 61.0 & 61.3 & 75.7 & 13.9 \\
\hline MJJAS & 301.4 & 296.6 & 288.6 & 354.9 & 67.1 \\
\hline
\end{tabular}

Mean values of monthly precipitation sum from May to September in 1961-2000 are shown in Fig. 4 on the basis of the FMI_grid dataset and in Table 3 for all three observational datasets. A distinct feature is a minimum in precipitation in May and a maximum in August. Differences between the 

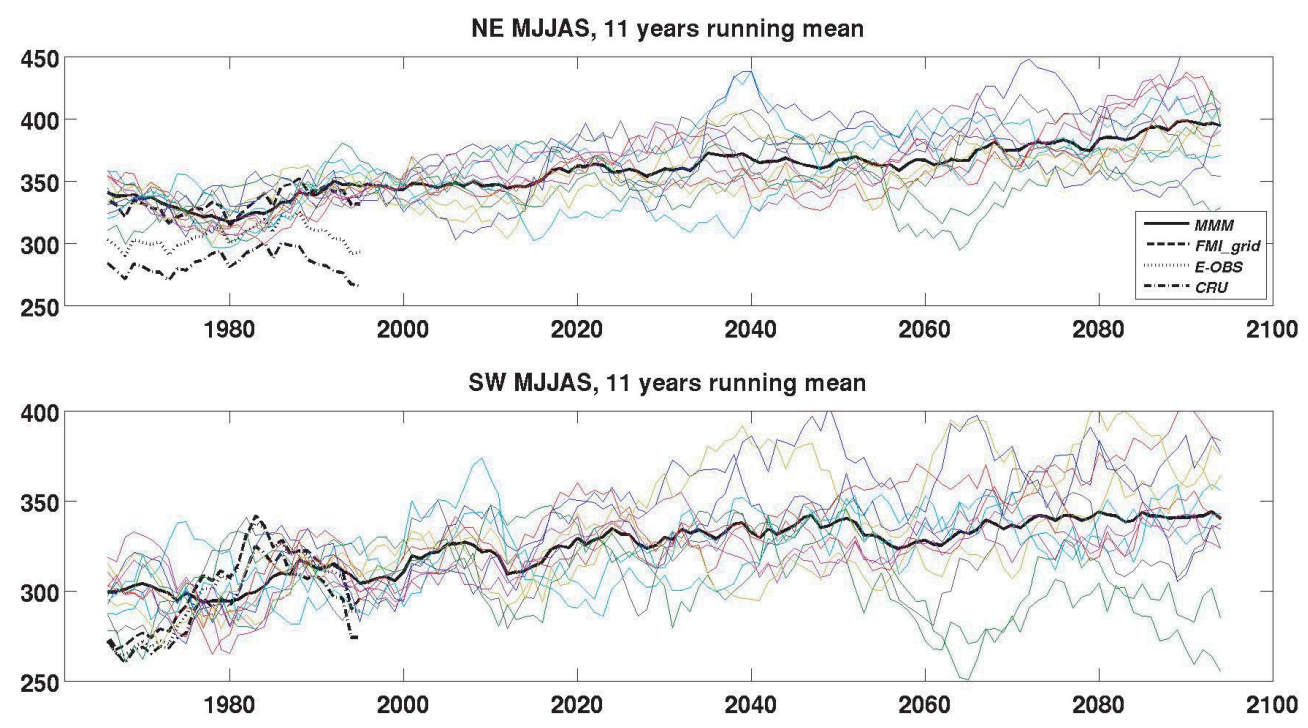

Fig. 5. Observed and simulated 11-year running means for the MJJAS precipitation sum. The model simulations are scaled so that the mean value in 1961-2000 corresponds to the mean value of FMI_grid, the inter-annual is not scaled directly. Multi-model-mean (MMM) is heavily smoothed and has smaller inter-annual variability.

three observational datasets are larger for NE than for SW. For the NE region, $C R U$ gives the smallest precipitation values and FMI_grid the highest. For the SW region, differences between the three observational datasets are very small, with the best agreement in September. This gives added reliability to the observations for SW.

\subsection{Model performance}

Model performance was evaluated simply by comparing the simulated precipitation sums and ensemble standard deviations during the baseline period 1961-2000 to those from the observed datasets, especially to FMI_grid. The models commonly overestimate precipitation (Table 3). As an exception, the multi-model-mean is very close to the observed values for SW in July. In many cases, the multi-model-mean bias exceeds the variability between the individual simulations, described by the standard deviation between the individual simulations. The bias is largest in May and September, and is smallest in August for the NE region, July and August for the SW region. These findings apply for both absolute and fractional biases and are independent of the observational dataset used. In general, the bias is smallest when compared with the FMI_grid dataset and largest when compared with the $C R U$ dataset, this bias is more pronounced for NE.

Each individual climate simulation indicates a marked difference in the precipitation amounts between the two areas (not shown). Apart from some simulations for May, the simulated precipitation values are systematically higher for NE. In the observed datasets, this is a general feature only for May and June and pronouncedly in MJJAS for FMI_grid (Table 3). After the analysis of the bias, the scaling method was applied to make the control period mean precipitation sums in the simulations equal to the observed sums.

\subsection{Future changes in precipitation sum and trends}

Precipitation has a large inter-decadal variability, which makes it difficult to estimate future precipitation deterministically. Smoothing or averaging of the time series is required to study the low-frequency signal of interest. Figure 5 shows running 11-year mean seasonal MJJAS precipitation sums for both areas. The figure clearly shows a gradual increase in the multi-model-mean precipitation, but also an increase in the variation, that is, the difference in the climate change signal, between the individual simulations over time. To acquire an insight how future precipitation will develop, both mean values and linear trends are analysed. Long-term trends from simulations are also compared with the observed FMI_grid dataset, which, together, provides a time series of almost 200 years.

According to the multi-model-mean trends over the 140year time period 1961-2100, precipitation will increase both for SW and NE (Table 2). All trends are statistically significant at the 5\% level, p-values ranging from less than 0.001 in May, June, July and MJJAS (and in September for NE) to 0.05 in August. In general, the increase in rainfall is somewhat larger for NE, where all simulations indicate positive trends, except for August and September. Also, as is evident from Fig. 5, the variation in the MJJAS future simulated trends is quite large for SW. The multi-model-mean trend values vary from $0.4 \mathrm{~mm} / 10$ years in August for both regions to $1.1 \mathrm{~mm} / 10$ years in July for SW (Table 2). It is important to note, however, that the multi-model-mean is highly 
smoothed and hence has a much smaller inter-annual variability. Compared with the observed long-term trend obtained from FMI_grid, the simulated MJJAS trends are remarkably similar, although the time periods and thus the forcing conditions are different. Only for July and August are trends positive in the two regions for both simulations and the observations, otherwise, months with long-term positive trends in the simulations do not often match the months with observed positive trends.

For the future scenario period 2061-2100, mean values were also calculated from the simulations using the delta change method. The multi-model-mean values of the change and the standard deviation between the simulations are presented in Fig. 6. A two-sided $t$-test with a 5\% significance level was applied to study the significance of the multimodel-mean changes.

Figure 6 shows the uneven increase in precipitation within the growing season. The increase is statistically significant for all months except August, which has the lowest increase in precipitation for both areas. The fractional increase is greatest in May, whereas the absolute increase is largest in July for the SW region and May-June for the NE region. For $\mathrm{SW}$, the increase is much smaller during the early growing season months May and June and, because of this, the difference in the SW precipitation sum between the wettest and driest month of the growing season should increase modestly in the future. By contrast, the difference in NE precipitation is reduced between the early growing season (May and June) and August. The precipitation increase for NE, where the precipitation sums are also higher for the present-day climate, is greater than for SW for all months except August. For the whole growing season precipitation sum, the multimodel-mean increase is larger for NE (almost $50 \mathrm{~mm}$ ) than for SW (about $35 \mathrm{~mm}$ ). The increase is statistically significant for both areas, even though the standard deviation between the individual simulations is larger for $\mathrm{SW}(30 \mathrm{~mm})$ than for NE $(21 \mathrm{~mm})$. The standard deviation of the multimodel-mean also varies with month, being larger in JulyAugust for SW and in May for NE.

\section{Discussion}

\subsection{Observational datasets and data analysis}

Since the observational datasets differ from each other in many ways, the used dataset has to be selected individually for each problem at hand. The difference between the datasets is also evident in this study and especially so for NE, which may be explained by the lower station density there (Fig. 2). The uncertainty caused by interpolation increases as the spatial resolution of the dataset decreases. In addition, the number of observing stations for NE varies in the different datasets. This can have a major effect to the estimation of grid-box average values if the topography or precipitation distribution inside the area is spatially very heterogeneous.
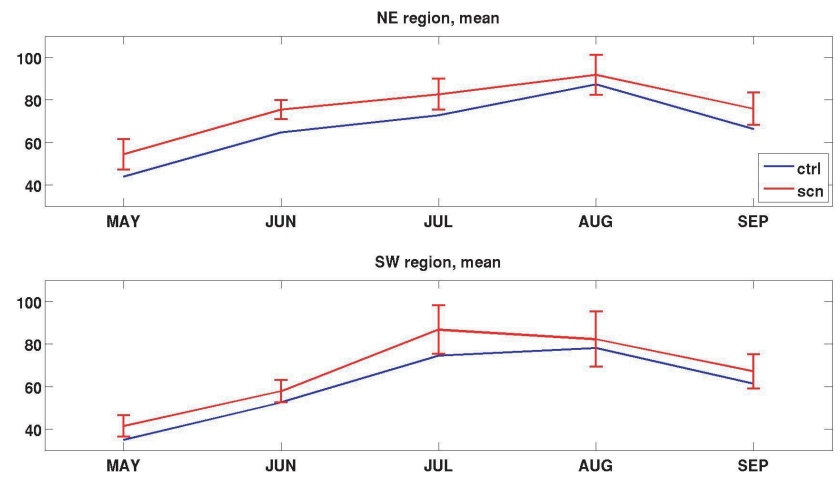

Fig. 6. Mean monthly precipitation for NE (top) and SW (bottom), as observed in 1961-2000 (blue) and as projected for 2061-2100 using the multi-model-mean results (red). The standard deviation between the individual model projections is indicated by the vertical bars.

The FMI_grid dataset has three important advantages over the other datasets: a higher spatial resolution, because it includes more observing stations within Finland; a longer time series; the mean precipitation values appear to be larger. Ad hoc, this third point is desirable considering that the observed datasets presumably include uncertainties that stem both from undercatchment of the actual rainfall, and error from the interpolation procedure (Haylock et al., 2008). The overall uncertainty appears to be the smallest for the FMI_grid dataset.

When comparing Tables 2 and 3, CRU has the lowest precipitation sums and for most time periods also the lowest trends. Since the time periods include both positive and negative trends, this is mostly coincidence related to the spatial variability of the summer precipitation, different number of station observations used and the limited length of the time series. For positive trends, such as MJJAS for SW, it could, in principle, also be possible that a small part of the difference in trends would be systematic related to the different observation station characteristics and the fractional difference between the precipitation sums. However, in this particular case, the bias of the mean is small and the difference of the datasets for each single year rather randomly distributed around that value, containing both positive and negative numbers. The difference in the trends is a good example of the sampling error caused by the limited length of the analysed time periods and the large inter-annual variability of summer precipitation in Finland, which has to be considered when interpreting the results. The lower signal-to-noise ratio of the precipitation changes compared to temperature changes causes sampling errors in the linear trend estimate and this ratio is lower for shorter time period. On the areas studied, the 40-year period growing season trend estimate seems to be dependent on the observational dataset, even though the dataset does not affect the significance of the trends. 
Use of the delta change method for removing the bias in the climate simulations is assumed here to be justifiable for monthly data, as the monthly variability of precipitation is much more normally distributed than the variability of daily data (Yang et al., 2010). Since the precipitation amounts between the two 40-year periods considered are different and the method uses a constant fraction to remove the bias, the amount of correction (in mm) is also different. This, in turn, weakly affects the magnitude (in $\mathrm{mm}$ ) of the simulated trend and the difference in the two 40-year precipitation means.

Also, it is important for the users of these results (e.g. Figs. 5 and 6) to understand that the modelling uncertainty provided by the ensemble is likely to underestimate the actual uncertainty. There are two important reasons for this. Firstly, the total number of climate simulations in this study is fairly small. Even if there were more simulations, such as in the CMIP3 (The Third Coupled Model Intercomparison Project) dataset (Meehl et al., 2007), the modelling uncertainty is still likely to be an underestimate (e.g. Knutti, 2008). Secondly, and more importantly, the simulations are not independent from each other because the number of driving GCMs is fairly small (Table 1). Therefore, these results and their uncertainty require careful interpretation.

\subsection{Conditions for agricultural crop production}

In general, recorded past precipitation trends have been favourable for Finnish crop production. Coastal regions in south-western Finland typically suffer from early summer drought during the major period of yield determination in spring sown seed crops (Peltonen-Sainio et al., 2009b). Observations suggest that the early summer drought has eased off slightly in the SW area, particularly so during 19612000. The observed increase in June precipitation was as high as $5-9 \mathrm{~mm}$ per decade, depending on the dataset (Table 2) and, based on Peltonen-Sainio et al. (2010), an increase of $8 \mathrm{~mm}$ per decade in early summer precipitation, as shown by FMI_grid, increases yields in spring cereals, barley, oat (Avena sativa L.) and wheat (Triticum aestivum L.) by some $140-230 \mathrm{~kg} / \mathrm{ha}$ depending on the species. Hence, such changes in precipitation may alone contribute by up to $15-20 \%$ of the recorded increases in cereal yields that averaged $1000-1600 \mathrm{~kg} / \mathrm{ha}$ in total during 1961-2000 (PeltonenSainio et al., 2009c).

In the future, prominent increases in precipitation are needed in early summer for growth and yield determination of the crops that are estimated to have markedly improved yield potentials and biomass production capacities (Peltonen-Sainio et al., 2009b). Higher biomasses, together with elevated temperatures, will cause higher pressure for evapotranspiration. Therefore, it is uncertain whether the projected future increases in precipitation (Fig. 6) are sufficient to meet the increased demands of more abundant crop stands.
Recorded past changes in May precipitation (Table 2) are too insignificant to cause any major support or challenge for seedling emergence and early plant stand establishment. The observed trend in reduced precipitation during August and September for both SW and NE indicates a slight reduction in risk for the harvest and quality of seed crops, but in the long term, future projections suggest an increase in precipitation. Winter cereals, rye (Secale cereale L.) and wheat, are harvested in August while harvests of spring cereals and rapeseed (Brassica sp.) typically take place in late August and early September. Reductions in the observed AugustSeptember precipitation amounts have been more prominent for NE than SW (Table 2), but SW is a more important region for seed crop production region in Finland due to its longer growing season and therefore, higher yield potential and production intensity. Only the most early maturing barley cultivars are grown in NE, whereas all seed crops that can be grown in Finland are produced in SW.

\section{Conclusions}

This study exploited the output of the regional climate simulation ensemble developed in the ENSEMBLES project to provide information on precipitation changes in Finland during the growing season. The results have a range of applications, including agriculture. In addition to 13 regional climate simulations, a gridded observational dataset developed in the ENSEMBLES project was utilized, as well as a very high-resolution $10 \times 10 \mathrm{~km}$ precipitation dataset, based on observations in Finland during 1908-2008. The third observational dataset was provided by $C R U$.

The study was performed for two areas, one located in north-eastern (NE) and the other in south-western (SW) Finland. Statistically significant positive long-term trends for precipitation from 1908 to 2008 were found for SW in June, and for NE in May, July and MJJAS. During 1961-2000, the only statistically significant increasing trend was found for SW in June. For NE, negative trends in August and September were statistically significant. The MJJAS trend was positive for SW, and negative for NE, but neither of these was found to be significant.

The simulated present-day precipitation amounts appeared to be larger than observed for all time periods except for SW in July. The month with the smallest bias was July for SW and August for NE. For SW, which is one of the most important agricultural regions in Finland regarding high field crop production intensity, the projected future precipitation is expected to show a statistically significant increase throughout the growing season, but not in the most favourable way for agriculture. The largest projected absolute increase is for July, implying that the difference between the wettest and driest month during the growing season will probably increase, whereas the largest projected fractional increase is in May, for which the extra precipitation will be the most beneficial for crop productivity. 

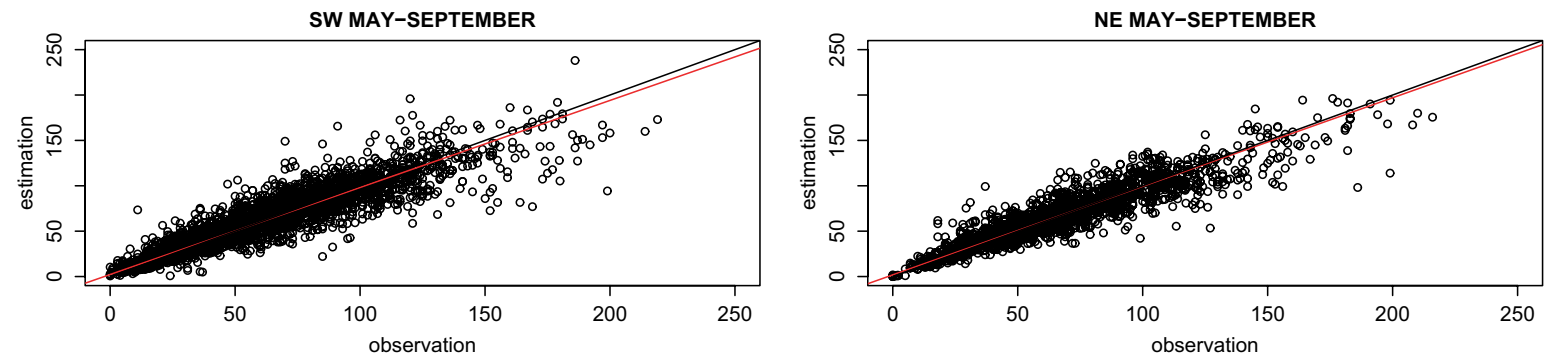

Fig. A1. Scatter plots of the observed and estimated precipitation values during 1971-2000.

The differences between the two areas are remarkable in many aspects. Precipitation amounts are larger for NE, both in the present-day climate and for the projected future increase. The difference between the observational datasets also appears to be greater for the more continental region of $\mathrm{NE}$, as is the bias in the present-day climate simulations. The larger differences for NE between the observational datasets are most likely related to the smaller number of stations in this region.

One of the three observational datasets had been developed at the Finnish Meteorological Institute and is described in Appendix A. The datasets have different spatial resolutions with implications for their performance and they are also markedly different, especially for NE. The FMI_grid dataset has the largest precipitation amounts, which is, in principle, desirable since it is expected to reduce the systematic bias in the observations related to the measurement and interpolation errors. Also, the selection of the dataset clearly affects the 40-year linear trends.

The convective origin and a strongly varying spatial distribution are characteristic for precipitation during the growing season in Finland. Also, precipitation climate in the study areas has a large inter-decadal variability, which emphasizes the need to use long time series when examining past trends in precipitation and making projections for the future.

\section{Appendix A}

\section{Description of the FMI_grid observational dataset}

To obtain a long, continuous time series, monthly precipitation sums were interpolated to a regular grid using the kriging interpolation technique (Matheron, 1963). In the 1980s, Ojansuu and Henttonen (1983) compared three different spatial smoothing methods for Finnish climatological data, a method of moving averages, a trend surface model, and a model combining these two. The combination model was found to be the most suitable for calculating long time series, because it gave the most reliable results with respect to time.

The model applied in this study was developed for climatological applications by Henttonen (1991) and follows the theoretical approach of Ripley (1981). A trend surface model is combined with a covariance function that smoothes the differences between the measured and the estimated values. The following external forcing parameters were used in the model; the geographical coordinates (latitude and longitude), the elevation of the terrain, and the percentage of sea in each grid box. The model has previously been used for research projects, e.g., by Tietäväinen et al. (2009), Vajda (2007), Venäläinen et al. (2005), Vajda and Venäläinen (2003), and Venäläinen and Heikinheimo (1997).

Besides from Finnish observation stations, monthly precipitation data were also collected from Russian stations near the Finnish border, obtained through the web-service of ECA\&D (Klein Tank et al., 2002). The resolution for the model was $10 \mathrm{~km}$. The interpolation area covered the part of Finland that is located south of latitude $65^{\circ} \mathrm{N}$.

\section{A1 Validation of the spatial model}

The interpolated precipitation values were validated against the observed monthly precipitation sums using data from the period 1971-2000. Data for validation were collected from the 54 stations located in SW and the 33 stations located in $\mathrm{NE}$ and station observations were compared with the interpolated values at the station locations.

Figure A1 shows the comparison of the observed and the estimated values for MJJAS (from May to September). The scatter plots start to diverge for large precipitation values and, thus, the monthly extremes are the hardest to estimate. The following skill scores were calculated; the mean absolute error (MAE), the root-mean-square error (RMSE) and the compound relative error (CRE), that measure the average error $(\mathrm{mm})$ and the deviation $(\mathrm{mm})$ of the spatial model, and the similarity between the observed and estimated values, respectively (Fig. A2). All quantities were calculated as modelled minus observed value. MAE, RMSE and CRE have their maximum values in July, minimum in May. This is consistent with the monthly precipitation sums (Fig. A2) as the heaviest rainfall in summer occurs during July and August, with May, June and September being drier. Similarly, the spatial model performs better in early and late summer than in July or August. 

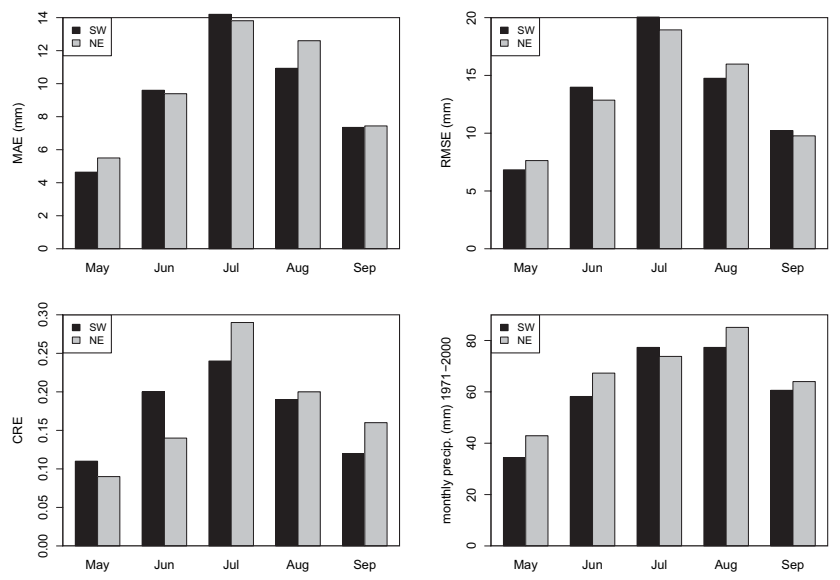

Fig. A2. Skill scores and the average monthly precipitation sums calculated over the 30-year period 1971-2000 for SW and $\mathrm{NE} . \mathrm{MAE}=$ mean absolute error, $\mathrm{RMSE}=$ root-mean-square error, $\mathrm{CRE}=$ compound relative error.

\section{A2 Uncertainty due to the uneven distribution of stations}

The uneven distribution of the observing stations in both space and time affects the quality of the estimated precipitation. The influence of the station network on the monthly precipitation sums was calculated by comparing monthly rainfall for the period 1971-2000 from the whole network, and from a limited subset of stations. The subset was chosen to mimic the sparser station network for the early period. This required the reasonable assumption that the spatial distribution of precipitation has not changed significantly during the study period. In order to make the comparison, only those stations that were operational in the reference period 19712000 could be included in the station subset representing the earlier periods. However, in the final analysis, all available station observations were used and, therefore, the spatial coverage of the observations was somewhat better than the comparison would suggest. This is why the comparison is likely to give a slight overestimation of the error and uncertainty.

Interpolations were performed for the whole area of Finland located south of $65^{\circ} \mathrm{N}$ using all the available station observations from Finland and the Russian border (Fig. 2). Data for the study regions used in this work were collected later from the interpolated grids. Thus, even in the early 20th century, when the number of observation stations for SW and NE was fairly small (Fig. 2) it was possible to derive the estimated precipitation for the regions.

In summary, the station network available in the early 20th century, with 80 stations over the whole interpolation area ( 5 in SW and 1 in NE), already provides a reasonable estimation of the monthly precipitation. In Fig. A3, the uncertainty
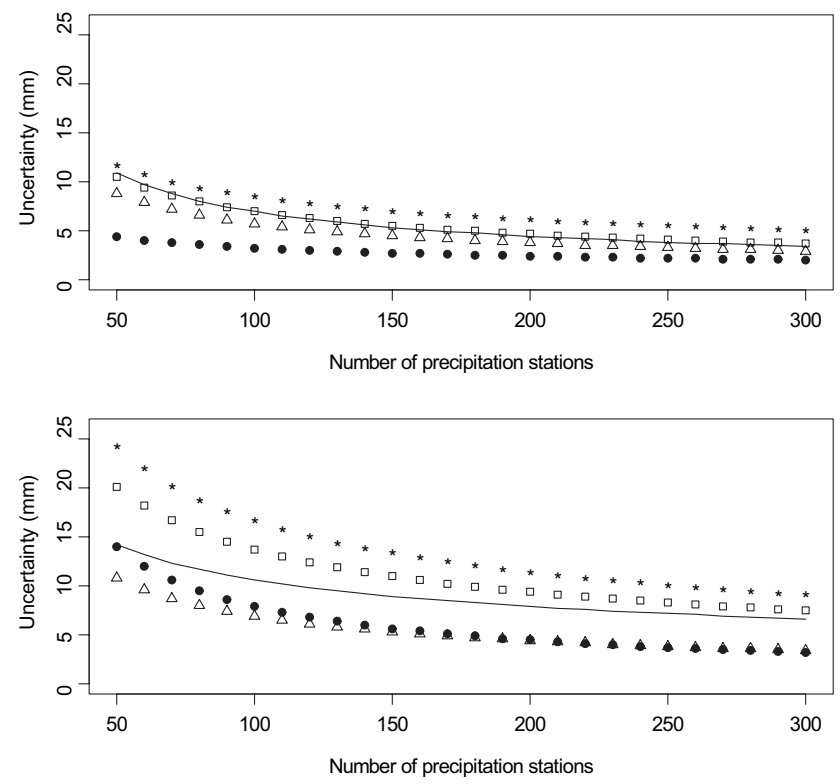

Fig. A3. Monthly precipitation uncertainties (mm) for SW (top) and NE (below) due to the limited station network as a function of the number of observation stations in the whole interpolation area (Finland, south of $\left.65^{\circ} \mathrm{N}\right)$. May = filled circles, June = solid line, July $=$ asterisk, August $=$ open square, September $=$ open triangle.

in the monthly mean precipitation sums for SW and NE related to the limited station network is given as a function of the number of stations in the whole interpolation area and for the beginning of the 20th century, the uncertainties vary from $5 \mathrm{~mm}$ (SW in May) to $25 \mathrm{~mm}$ (NE in July). Generally, the greatest uncertainties are in July and August, coinciding with the highest precipitation. The higher uncertainties found in NE are due to the sparser station network.

Acknowledgements. The ENSEMBLES data contained in this study was funded by the EU FP6 Integrated Project ENSEMBLES (Contract number 505539), whose support is gratefully acknowledged. We acknowledge the E-OBS dataset from the EU-FP6 project ENSEMBLES (http://www.ensembles-eu.org) and the data providers in the ECA\&D project (http://eca.knmi.nl). This research has been supported by the Academy of Finland (decision 127239), Kone Foundation is also acknowledged for providing funding for this study. Ewan O'Connor is acknowledged for linguistic review of this paper. The two referees and the editor are thanked for their valuable comments.

Edited by: G. Leckebusch

Reviewed by: G. Tetzlaff and another anonymous referee 


\section{References}

Accadia, C., Mariani, S., Casaioli, M., Lavagnini, A., and Speranza, A.: Sensitivity of precipitation forecast skill scores to bilinear interpolation and a simple nearest-neighbour average method on high-resolution verification grids, Weather Forecast., 18, 918932, 2003.

Andersen, H. E., Kronvang, B., Larsen, S. E., Hoffmann, C. C., Jensen, T. S., and Rasmussen, E. K.: Climate-change impacts on hydrology and nutrients in a Danish lowland river basin, Sci. Total Environ., 365, 223-237, 2006.

Carter, Leckebusch, Olesen, Bindi, et al.: Making sense of multimodel climate projections for impact and adaptation assessment: investigations in the ENSEMBLES project, Nat. Hazards Earth Syst., in preparation, 2010.

Christensen, J. H. and Christensen, O. B.: A summary of the PRUDENCE model projections of changes in European climate by the end of this century, Springer, Climatic Change, 81, 7-30, 2007.

Goodess, Carter, Klein Tank, Royer, Cubasch, Hoeschel, Voldoire, Christensen, Rummukainen, Jacob, Lorenz, et al. Preparation, analysis and delivery of the ENSEMBLES regional climate projections and observations for use in impact and adaptation assessments, Nat. Hazards Earth Syst., submitted, 2010.

Haylock, M. R., Hofstra, N., Klein Tank, A. M. G., Klok, E. J., Jones, P. D., and New, M.: A European daily highresolution gridded data set of surface temperature and precipitation for 1950-2006, J. Geophys. Res., 113, D20119, doi:10.1029/2008JD010201, 2008.

Heino, R.: Ilmastollisten perussuureiden vuorokausi - ja vuosivaihtelusta Suomessa - Diurnal and annual variations of climatic elements in Finland, Tutkimusseloste 110, Ilmatieteen laitos, 142 pp., 1983 (in Finnish).

Heino, R.: Climate in Finland during the period of meteorological observations, Finnish Meteorological Institute Contributions, 12, 209 pp., 1994.

Henttonen, H.: Kriging in Interpolating July Mean Temperatures and Precipitation Sums, Reports from the Department of Statistics University of Jyväskylä, Finland, publication no. 12, 41 pp., 1991.

Jacob, D., Bärring, L., Christensen, O. B., Christensen, J. H., de Castro, M., Déqué, M., Giorgi, F., Hagemann, S., Hirschi, M., Jones, R., Kjellström, E., Lenderink, G., Rockel, B., Sánchez, E., Schär, C., Seneviratne, S. I., Somot, S., van Ulden, A., and van den Hurk, B.: An inter-comparison of regional climate models for Europe: design of the experiments and model performance, Climatic Change, 81, 31-52, 2007.

Kendon, E. J., Rowell, D. P., and Jones, R. G.: Mechanisms and reliability of future projected changes in daily precipitation, Clim. Dynam., in press, doi:10.1007/s00382-009-0639-z, 2009.

Klein Tank, A. M. G., Wijngaard, J. B., Können, G. P., Böhm, R., Demarée, G., Gocheva, A., Mileta, M., Pashiardis, S., Hejkrlik, L., Kern-Hansen, C., Heino, R., Bessemoulin, P., MüllerWestermeier, G., Tzanakou, M., Szalai, S., Pálsdóttir T., Fitzgerald, D., Rubin, S., Capaldo, M., Maugeri, M., Leitass, A., Bukantis, A., Aberfeld, R., van Engelen, A. F. V., Forland, E., Mietus, M., Coelho, F., Mares, C., Razuvaev, V., Nieplova, E., Cegnar, T., Antonio López, J., Dahlström, B., Moberg, A., Kirchhofer, W., Ceylan, A., Pachaliuk, O., Alexander, L. V., and Petrovic, P.: Daily dataset of 20th century surface air temperature and precip- itation series for the European climate assessment, Int. J. Climatol., 22, 1441-1453, doi:10.1002/joc.773, 2002.

Knutti, R.: Should we believe in model predictions of future climate change?, Philos. T. R. Soc. A 366, 4647-4664, 2008.

Lenderink, G. and Van Meijgard, E.: Increase in hourly precipitation extremes beyond expectations from temperature changes, Nat. Geosci., 1, 511-514, 2008.

Matheron, G.: Principles of geostatistics, Econ. Geol., 58, 12461266, 1963.

Meehl, G. A., Covey, C., Delworth, T., Latif, M., McAvaney, B., Mitchell, J. F. B., Stouffer, R. J., and Taylor, K. E.: The WCRP CMIP3 Multimodel Dataset: A New Era in Climate Change Research, B. Am. Meteorol. Soc., 88, 1383-1394, 2007.

Mitchell, T. D. and Jones, P. D.: An improved method of constructing a database of monthly climate observations and associated high-resolution grids, Int. J. Climatol., 25, 693-712, 2005.

Nakićenović, N., Davidson, O., Davis, G., Grubler, A., Kram, T., La Rovere, E. L., Metz, B., Morita, T., Pepper, W., Pitcher, H., et al.: Special Report on Emissions Scenarios, Cambridge Univ. Press, Cambridge, UK, 2000.

Ojansuu, R. and Henttonen, H.: Estimation of local values of monthly mean temperature, effective temperature sum and precipitation sum from the measurements by the Finnish Meteorological Office, Silva Fenn., 17, 143-160, 1983 (in Finnish with English summary).

Peltonen-Sainio, P., Rajala, A., Känkänen, H., and Hakala, K.: Improving farming systems in northern European conditions, in: Crop Physiology: Applications for Genetic Improvement and Agronomy, edited by: Sadras, V. O. and Calderini, D., Elsevier, Amsterdam, The Netherlands, 71-97, 2009a.

Peltonen-Sainio, P., Jauhiainen, L., Hakala, K., and Ojanen, H.: Climate change and prolongation of growing season: changes in regional potential for field crop production in Finland, Agr. Food Sci., 18, 171-190, 2009b.

Peltonen-Sainio, P., Jauhiainen, L., and Laurila, I. P.: Cereal yield trends in northern European conditions: Changes in yield potential and its realisation, Field Crop. Res., 110, 85-90, 2009c.

Peltonen-Sainio, P., Jauhiainen, L., and Hakala, K.: Crop responses to precipitation and elevated temperatures in cool growing conditions at high latitudes according to long-term multi-location trials, J. Agr. Sci., in press, 2010.

Ripley, B. D.: Spatial Statistics, Wiley, New York, 1981.

Rowell, D. P.: A scenario of European Climate Change For The Late Twenty-First Century: Seasonal Means And Interannual Variability, Springer Verlag, Clim. Dynam., 25, 837-849, 2005.

Ruokolainen, L. and Räisänen, J.,: Probabilistic forecasts of nearterm climate change: sensitivity to adjustment of simulated variability and choice of baseline period, Tellus A, 59, 309-320, 2007.

Räisänen, J. and Joelsson, R.: Changes in average and extreme precipitation in two regional climate model experiments, Tellus A, 53, 547-566, 2001.

Räisänen, L., Ruokolainen, L., and Ylhäisi, J.: Weighting of model results for improving best estimates of climate change, Clim. Dynam., in press, doi:10.1007/s00382-009-0659-8, 2010.

Sneyers, R.: On the Statistical Analysis of Series of Observations, Secretariat of the World Meteorological Organization, Geneva, Switzerland, WMO Technical Note 143, 1990. 
Solantie, R.: The climate of Finland in relation to its hydrology, ecology and culture, Finnish Meteorological Institute, Helsinki, Finland, Finnish Meteorological Institute Contributions 2, 130 pp., 1990.

Solantie, R. and Junila, P.: Sademäärien korjaaminen Tretjakovin ja Wildin sademittarien vertailumittausten avulla, Summary in English: The correction of precipitation measurements based on comparisons between Tretyakov and Wild gauges, Finnish Meteorological Institute, Meteorological Publications, 33, 142 pp., 1995 (in Finnish).

Tietäväinen, H., Tuomenvirta, H., and Venäläinen, A.: Annual and seasonal mean temperatures in Finland during the last 160 years based on gridded temperature data, Int. J. Climatol., in press, doi:10.1002/joc.2046, 2009.

Tuomenvirta, H., Drebs, A., Förland, E., Tveito, O.-E., Alexandersson, H., Vaarby Laursen, E., and Jónsson, T.: Nordklim data set 1.0 - description and illustrations, DNMI Report 08/01, 26 pp., 2001.

Tuomenvirta, H.: Reliable estimation of climatic variations in Finland, Finnish Meteorological Institute contributions, publication no. 43, 80 pp. +78 pp. appendix, 2004.

Vajda, A. and Venäläinen, A.: The influence of natural conditions on the spatial variation of climate in Lapland, northern Finland, Int. J. Climatol., 23, 1011-1022, doi:10.1002/joc.928, 2003.
Vajda, A.: Spatial Variation of Climate and the Impact of Disturbances on local climate and forest recovery in northern Finland, Finnish Meteorological Institute Contributions, publication no. 64, 140 pp., 2007.

Van der Linden, P. and Mitchell, J. F. B (Eds.): ENSEMBLES: Climate Change and its Impacts: Summary of research and results from the ENSEMBLES project, Met Office Hadley Centre, Exeter, UK, 160 pp., 2009.

Venäläinen, A. and Heikinheimo, M.: The spatial variation of longterm mean global radiation in Finland, Int. J. Climatol., 17, 415426, 1997.

Venäläinen, A., Tuomenvirta, H., Pirinen, P., and Drebs, A.: A Basic Finnish Climate Data Set 1961-2000 - Description and Illustrations, Finnish Meteorological Institute Reports, report no. 5, 27 pp., 2005.

Von Storch, H. and Zwiers, F. W.: Statistical Analysis in Climate Research, Cambridge University Press, 499 pp., 1999.

Yang, W., Andréasson, J., Graham, L. P., Olsson, J., Rosberg, J., and Wetterhall, F.: Distribution based scaling to improve usability of RCM projections for hydrological climate change impacts studies, Hydrol. Res., in press, 2010. 